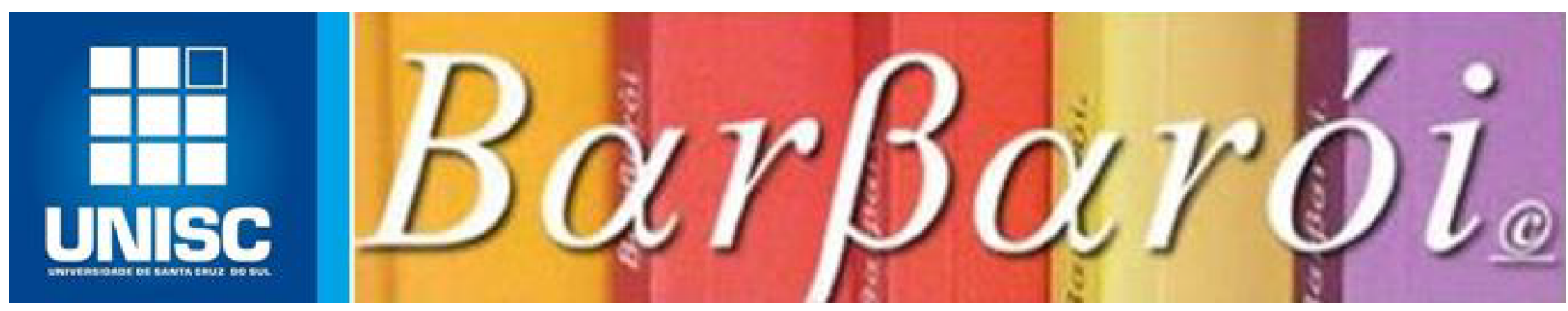

\title{
RELATO E TRANSFORMAÇÃO: O PROCESSO DE RECONHECIMENTO DA UNIVERSIDADE DE SANTA CRUZ DO SUL
}

\author{
DOI: http://dx.doi.org/10.17058/barbaroi.v0i59.16979
}

\author{
$*$ \\ Wilson Kniphoff da Cruz \\ Universidade de Santa Cruz do Sul - UNISC-Brasil
}

\section{Resumo:}

O texto, além de uma pequena apresentação, compreende uma republicação de um artigo publicado inicialmente no número zero da Revista BARBARÓI. Naquele artigo, o seu autor, professor Wilson Kniphoff da Cruz, resgata aspectos do seu comprometimento com o ensino superior comunitário em Santa Cruz do Sul, registrando os diferentes momentos que antecederam à criação da UNISC, em 1993: a mobilização da comunidade acadêmica, as dificuldades burocráticas no encaminhamento do projeto Universidade, a formação de uma Comissão Interna para encaminhar o projeto, as visitas da COmissão de Acompanhamento do Conselho Federal de Educação, as mudanças acadêmica, o esforço na qualificação dos professores, as necessárias mudanças de mentalidade a partir da criação da Universidade. Ao apresentar esse resgate, o artigo é um convite à reflexão sobre as dinâmicas políticas que compreenderam a mobilização coletiva (especialmente da comunidade acadêmica) visando à criação de uma Universidade Comunitária em Santa Cruz do Sul

\section{Palavras-chave:}

Universidade Comunitária; Ensino Superior em Santa Cruz do Sul; UNISC

\section{Uma apresentação: por César Hamilton Brito Góes e Marco André Cadoná}

Enquanto participantes da equipe de editoração deste Número Especial da BARBARÓI, organizado para registrar a história do Departamento de Ciências Humanas na Universidade de Santa Cruz do Sul (UNISC), reeditamos um artigo do professor Wilson Kniphoff da Cruz, inicialmente publicado do número 0 da Revista Barbarói, em março de 1994. De forma gentil, mas também com o objetivo de avalizar um projeto de publicação que

Barbarói, Santa Cruz do Sul, n.59 - número especial, p.<10-24>, Ago./Set. 2021 
naquele momento os professores do Departamento de Ciências Humanas assumiram, o professor Wilson se propôs a escrever um artigo, analisando aspectos importantes do processo histórico de construção do projeto de Universidade Comunitária que sustentou a discussão e a própria fundação da UNISC, em 1993.

O professor Wilson foi o primeiro Reitor da UNISC. Sua trajetória profissional na FISC (Faculdades Integradas de Santa Cruz), no entanto, teve início ainda durante a década de 1970, mais precisamente em 1976, quando passou a desenvolver atividades de ensino e de pesquisa na Instituição. Ciente da necessidade da qualificação do corpo docente da FISC, ainda em 1979 o professor Wilson iniciou o seu Mestrado, no Programa de Pós-Graduação em Ciências Físico-Química, da Universidade Federal de Santa Catarina (UFSC), tornando-se Mestre em 1980. Durante as décadas de 1980 e de 1990, o professor Wilson atuou na UNISC, enquanto professor, pesquisador e gestor. E em 2000, então, iniciou seu doutoramento, no Programa de Pós-Graduação em Engenharia de Produção da Universidade Federal de Santa Catarina (UFSC), o qual terminou em 2004, defendendo sua tese sobre a "gestão da produção intelectual pelo método participativo" na UNISC.

No período entre 1987 e 1998, o professor Wilson assumiu a posição de maior relevância na administração universitária em Santa Cruz do Sul, primeiro enquanto Diretor Geral da FISC (período entre 1987 e 1992) e depois enquanto Reitor da UNISC (período entre 1993 e 1998). Foi ele, portanto, que liderou o grupo (formado principalmente por professores) que discutiu, elaborou, encaminhou e conseguiu a aprovação do projeto de criação da UNISC.

A criação da UNISC, em 1993, está diretamente vinculada à liderança política e intelectual do professor Wilson na história de construção do ensino superior em Santa Cruz do Sul e na Região do Vale do Rio Pardo. Sua representatividade na comunidade acadêmica, sua capacidade de articulação política com lideranças locais, estaduais e nacionais, sua visão acerca da importância e da necessidade de uma Universidade comprometida com o desenvolvimento regional, foram aspectos, certamente, importantes na criação de uma Universidade Comunitária em Santa Cruz do Sul.

No artigo que escreveu para a primeira edição da BARBARÓI, o professor Wilson resgata alguns aspectos desse seu comprometimento com o ensino superior comunitário em Santa Cruz do Sul. Nele encontramos um relato ("em ordem cronológica") do processo político que antecedeu à criação da UNISC, em 1993: a mobilização da comunidade acadêmica, as dificuldades burocráticas no encaminhamento do projeto de Universidade, a formação de uma Comissão Interna para encaminhar o projeto, as visitas da Comissão de Acompanhamento do Conselho Federal de Educação, as mudanças organizacionais e políticas Barbarói, Santa Cruz do Sul, n.59 - número especial, p.<10-24>, Ago./Set. 2021 
na Instituição, as repercussões dessas mudanças na comunidade acadêmica, o esforço na qualificação dos professores, as necessárias mudanças de mentalidade a partir da criação da Universidade.

Dentre esses aspectos ressaltados pelo professor Wilson, dois deles são destacados no encaminhamento de suas reflexões finais.

O primeiro está relacionado ao caráter regional da UNISC, presente desde sempre na história do Ensino Superior em Santa Cruz do Sul, mas potencializado com a criação da Universidade, em especial através da oportunidade de expansão das atividades de pesquisa e de extensão universitárias. A UNISC, nesse sentido, é resultado de uma visão de Universidade comprometida com o desenvolvimento regional, com a participação nas comunidades, com um olhar que se constrói a partir do diálogo e da atenção às necessidades, aos interesses, aos desejos que brotam da diversidade que constitui as regiões onde ela atua.

O segundo deles remete a uma das principais mudanças que ocorreram na criação da UNISC: as mudanças políticas decorrentes do compromisso com uma gestão democrática. O professor Wilson lembra em seu artigo que o Diretor-Geral da FISC - Faculdades Integradas em Santa Cruz do Sul - era escolhido pelo presidente da Mantenedora, "não havendo a participação de professores, alunos e funcionários" nessa escolha, nem na escolha de uma "lista tríplice ou sêxtupla". No processo de construção da UNISC essa cultura política mudou radicalmente, e a democracia na gestão universitária colocou-se como um princípio orientador da concepção e da prática concreta de construção da Universidade. A partir de então, coordenadores de curso, chefes de Departamento, mas também a própria Reitoria, passaram a ser escolhidos através da participação direta da comunidade acadêmica. Sabendo da importância desse processo político e da importância da democracia como um valor fundamental para e na Universidade, o professor Wilson encaminha o final do artigo com um convite, mas, também, com uma espécie de alerta:

\footnotetext{
A democracia hoje existente deve ser defendida por todos os integrantes da comunidade universitária. A forma de escolha dos dirigentes da UNISC, por eleições diretas, envolvendo todos os alunos, funcionários, professores e membros da Assembleia Comunitária da APESC, já demonstrou os seus aspectos positivos [...]. Essa forma de escolha dos dirigentes não garante a solução dos problemas nem o desenvolvimento institucional. O que se observa, no entanto, aqui na UNISC, é que os processos eleitorais têm servido para uma reflexão sobre a realidade da Instituição e para a tomada de posições que tem proporcionado as bases para as administrações [...].

Esta particularidade que se observa na UNISC revela que o mandato pertence à entidade e que os compromissos assumidos pelos candidatos durante a campanha eleitoral devem ser cumpridos depois.
}

Barbarói, Santa Cruz do Sul, n.59 - número especial, p.<10-24>, Ago./Set. 2021 
Os que nos antecedem têm o poder de nos lembrar de compromissos históricos importantes que as Instituições assumem, nos convidando, sempre, a avaliações cuidadosas acerca dos movimentos que nos distanciam desses compromissos. Desejamos que a leitura do texto do professor Wilson tenha esse espaço em nossas reflexões e que nos convide ao sempre importante compromisso crítico com o presente e o futuro da UNISC. Boa leitura.

\section{RELATO E TRANSFORMAÇÃO: O PROCESSO DE RECONHECIMENTO DA UNIVERSIDADE DE SANTA CRUZ DO SUL}

Prof. Wilson Kniphoff da Cruz Reitor da UNISC

Ao saber da publicação deste primeiro número da Revista Barbarói e do tema abordado colocamo-nos à disposição para escrever este artigo, pois achamos que deve ficar registrada esta parte da história da entidade.

Esperamos fazer uma descrição de todo o processo de transformação das Faculdades Integradas na Universidade de Santa Cruz do Sul que não pretende ser um trabalho de pesquisa, pois as fontes de informações disponíveis que existem na Assessoria da Reitoria não foram minuciosamente trabalhadas por não haver tempo disponível para isso, mas um simples relato daquilo que, na nossa opinião, aconteceu de mais importante nesta trajetória.

Pretendemos apresentar este relato em ordem cronológica para poupar os leitores de um exercício desnecessário de busca de localização temporal e somente por isso é que são citadas várias datas no desenvolvimento do tema.

Desde que foi criada a Associação Pró-Ensino em Santa Cruz do Sul surgiu a aspiração de se ter nesta região uma Universidade. Acreditava-se que uma mobilização comunitária aliada à interferência da classe política seria suficiente para a conquista da almejada Universidade. Lembramos os decalcos dos anos 70 com a frase "APESC rumo à Universidade" e do veículo da entidade, um Corcel, com este "slogan" estampado em suas portas.

Barbarói, Santa Cruz do Sul, n.59 - número especial, p.<10-24>, Ago./Set. 2021 
Paralelamente a esta forma de encarar o assunto, as Faculdades iam se aperfeiçoando, atendendo às exigências que a legislação apresentava especialmente através das solicitações da equipe de técnicos da DEMEC que periodicamente supervisionava a nossa IES ou da cobrança quando os cursos necessitavam de reconhecimento junto ao CFE. Estas exigências, aliadas à visão de alguns professores que ocupavam cargos diretivos na entidade, fizeram com que alguns alicerces se acumulassem e que tempos depois fossem sendo reconhecidos. Destes destacamos: a Biblioteca, os Laboratórios, a qualificação de pessoal, a tradição e a seriedade no ensino e a solidez administrativa e patrimonial.

A primeira tentativa de encaminhar uma carta-consulta ao CFE, atendendo ao que a legislação preconizava, aconteceu em 1984. O trabalho foi elaborado por um grupo ligado à Direção-Geral e foi apreciado por um consultor que acompanhava processos que tramitavam no CFE. O parecer foi de que o processo não tinha chances de aprovação naquela Conselho, pois não atendia a várias exigências que eram impostas.

Em 1985 e 1986 aconteceu uma mobilização de um grupo significativo formado especialmente por professores e alunos e que culminou com a democratização da instituição, com a conquista das eleições diretas para o provimento dos cargos de Diretor-Geral, Diretores de Faculdades e Chefes de Departamentos, resultando nas eleições gerais em 1986 e proporcionando uma série de alterações na sistemática de funcionamento das Faculdades Integradas.

O Diretor-Geral, antes do processo de democratização, era escolhido pelo presidente da Mantenedora, não havendo a participação de professores, alunos e funcionários e de nenhum órgão colegiado da FISC nesta escolha, nem na elaboração de lista tríplice ou sêxtupla.

A democratização apresentou reflexos positivos sobre o processo de reconhecimento da UNISC.

O primeiro passo efetivo aconteceu no primeiro semestre de 1987 quando se reuniram os professores no auditório central da FISC para uma análise da legislação relativa ao encaminhamento de carta-consulta para a transformação de Faculdades em Universidades e das condições que a entidade apresentava frente às exigências legais.

$\mathrm{Na}$ reunião promovida pela Direção-Geral, foi concluído por unanimidade dos presentes pela elaboração da carta-consulta com o compromisso de todos em promover as alterações necessárias para que todas as exigências fossem atendidas. Algumas mudanças foram imediatas e contribuíram em muito com o processo de reconhecimento da Universidade, das quais salientamos: a criação de um plano de qualificação dos professores;

Barbarói, Santa Cruz do Sul, n.59 - número especial, p.<10-24>, Ago./Set. 2021 
o aumento do número de professores com regime de trabalho com tempo integral e parcial; o estímulo ao desenvolvimento de atividades de pesquisa e extensão, tendo sido criado inicialmente a Coordenação de Extensão que posteriormente se transformou em Coordenação de Pesquisa e Extensão, depois em Superintendência e mais tarde na Pró-Reitoria de Pesquisa e Extensão.

Outra mudança foi a elevação do nível salarial, permitindo a contratação e a manutenção de professores e funcionários com maior qualidade e qualificação.

A elaboração da carta-consulta iniciou imediatamente. Foi organizado um grupo de trabalho ligado à Direção-Geral e criou-se uma Resolução que definia as instâncias de discussão e aprovação dos documentos que embasavam a carta-consulta. Mudanças estruturais eram necessárias, privilégios históricos deveriam ser eliminados, o centro de poder decisório em termos administrativos deveria ser deslocado, enfim, alterações profundas que exigiam que as regras do jogo estivessem muito bem definidas.

A Resolução 03/88 do CONEPE da FISC foi homologada pelo Colegiado Superior da FISC, pelo Conselho Superior e pela Assembleia Comunitária da APESC e apresentava as seguintes instâncias de tramitação e de aprovação para a carta-consulta:

I-Comissão Deliberativa

II - Assembleia de professores e presidente do DCE, DAs, da Associação dos Funcionários e da APUVARP

III - Conselho de Ensino, Pesquisa e Extensão

IV-Colegiado Superior da FISC

$V$ - Conselho Superior da APESC

VI-Assembleia Comunitária

Foram inúmeras reuniões que apreciaram o documento, parte por parte e instância por instância. Tudo foi discutido: Concepção de Universidade, Área de Influência; Espaço-físico e Recursos Materiais; Plano de Expansão para os próximos cinco anos referentes a professores, alunado e atividades acadêmicas; Situação e Planejamento Econômico-Financeiros e Modelo Organizacional.

É importante frisar bem que o projeto de Universidade encaminhado ao CEF é um projeto de toda a Universidade pois foi possível que todos os segmentos da entidade participassem efetivamente da sua elaboração e aprovação.

Concluída a carta-consulta, a mesma foi aprovada pela instância máxima, a Assembleia Comunitária, em 10/11/1988.

Barbarói, Santa Cruz do Sul, n.59 - número especial, p.<10-24>, Ago./Set. 2021 
Acontece que naquela época estava em vigor o Decreto n. 93.594 de 19/11/1986 que impedia o encaminhamento de cartas-consulta com o objetivo de criar novos cursos $e$ universidades em todo o território nacional. Insistentes pedidos para que se abrisse a possibilidade de encaminhamento de cartas-consulta foram feitos ao longo dos anos aos Delegados da DEMEC/RS, aos Secretários Gerais da Secretaria de Ensino Superior (SENESU) do Ministério da Educação, aos Ministros da Educação, ao Presidente do CFE e aos representantes da Região do Vale do Rio Pardo no Poder Legislativo da União.

A resolução n.06 de 05/12/1989, publicada no DOU em 07/12/89, abriu a possibilidade de encaminhar a nossa carta-consulta protocolada em 03/01/90.

Devido ao mau relacionamento entre o Ministério de Educação e a CFE e a consequente demora na definição da programação do mandato do Conselheiro Ernani Bayer, relator do nosso processo, a aprovação da carta-consulta aconteceu apenas em 19/02/1991 pelo CFE.

Conforme estabelecem as normas de reconhecimento, foram criadas, então, a Comissão de Acompanhamento pelo CFE e a Comissão Interna de Universidade pela FISC. A Comissão de Acompanhamento foi formada pela Conselheira Zilma Gomes Parente de Barros e pelos professores Genuíno Bordignon da Universidade de Brasília, Rogério Vahl da Universidade Federal de Santa Catarina e Evelcy Monteiro Machado da Universidade Federal do Paraná. Posteriormente, ainda no início do processo, o Conselheiro Raulino Tramontin substituiu a Conselheira Zilma e o Prof. Ely Carlos Petry da Universidade Luterana do Brasil substituiu o Prof. Bordignon. A Comissão Interna da Universidade foi formada pelos professores Elizabeth Rizzato Lara, Wilson Kniphoff da Cruz, Vilmar Thomé, Luiz Augusto Costa a Campis, Marcos Moura Baptista dos Santos, Rosa Glesse, Beatriz Menezes Sperb e Roque Neumann

O papel da Comissão Interna de Universidade foi o de estabelecer uma ligação entre a FISC e a Comissão de Acompanhamento, além da elaboração dos relatórios que eram solicitados por essa Comissão durante o período de acompanhamento. Sempre que se tornavam necessárias alterações mais profundas do que as previstas no plano original (carta-consulta), o assunto era encaminhado aos órgãos colegiados da FISC e da APESC, competentes para decidir sobre a questão, para que não se corresse o risco de uma descontinuidade no andamento do processo.

Foram ao todo nove visitas da Comissão de Acompanhamento e foram entregues os seguintes Relatórios:

I - O Projeto da Universidade

Barbarói, Santa Cruz do Sul, n.59 - número especial, p.<10-24>, Ago./Set. 2021 
II - As funções da Universidade

III - Recursos Humanos

IV-Recursos Materiais e Infra-Estrutura

V-Análise Organizacional da Estrutura Institucional

VI-Análise Organizacional da Estrutura Administrativa

VII - Ordenamentos Jurídicos

VIII - Ordenamento Jurídico-Transitório

IX - Planejamento Econômico e Financeiro

$X$ - Avaliação dos Cursos de Graduação

XI - Plano de Desenvolvimento Institucional de 1993 a 1997

A vida da FISC foi mudando e destacamos, nos parágrafos seguintes, as alterações mais significativas.

A redepartamentalização, acontecida em 18 de julho de 1991, aumentou a unidade da FISC e atendeu a uma das exigências legais da não-duplicação de meios para a obtenção de fins idênticos. Antes, os professores eram lotados nas quatro Faculdades existentes: Faculdade de Direito, com o curso de Direito e 505 alunos; a Escola Superior de Educação Física, com o curso de Educação Física e 198 alunos; a Faculdade de Ciências Contábeis e Administrativas com os Cursos de Administração, Ciências Contábeis e Economia com 1033 alunos e a Faculdade de Filosofia, Ciências e Letras com os cursos de Pedagogia, Estudos Sociais, Letras, Química e Química Industrial com 1021 alunos. O número de alunos citado é o do primeiro semestre de 1991. Naquela época um professor que trabalhasse uma disciplina em pelo menos um dos cursos de cada Faculdade pertencia a quatro departamentos diferentes, um em cada Faculdade. Depois os departamentos passaram a atender a todos os cursos, independente da Faculdade a qual estavam ligados, invertendo-se totalmente a ordem anterior e impedindo que um professor pudesse participar de mais do que um departamento.

Outra decisão, que marcou profundamente o processo, foi a da extinção das Faculdades que aconteceu em 04/03/92. O fato foi gerado quando da definição da estrutura da nova Universidade. A Comissão de Acompanhamento aceitaria a continuidade da existência de Faculdades, ou a reunião de Departamentos em Centros, desde que houvesse uma organização mais equilibrada e coerente, não sendo admitido de forma alguma que uma Faculdade possuísse apenas um curso. Foi difícil entender que os departamentos não possuem cursos, que os cursos são da Universidade, que os departamentos oferecem disciplinas para todos os cursos e finalmente que havia uma forma diferente de se organizar uma IES. A opção pela não-existência de uma estrutura intermediária, ligando-se os Barbarói, Santa Cruz do Sul, n.59 - número especial, p.<10-24>, Ago./Set. 2021 
departamentos diretamente à Reitoria, deve-se a várias razões entre as quais, o tamanho da Instituição - são apenas doze departamentos - e a dificuldade de se admitir um novo reagrupamento, se destacaram. Simultaneamente à extinção das Faculdades, foi adotada a estrutura da Coordenação de Curso e Colegiado de Curso apresentando um equilíbrio maior tanto de representatividade nos órgãos decisórios da FISC, quanto de desenvolvimento das atividades didático-pedagógicas ocorrido pela assistência que cada Coordenador de Curso passou a prestar aos professores e alunos a ele ligados.

A mudança do centro de poder decisório em assuntos administrativos e financeiros também teve uma repercussão muito grande na forma de funcionamento da entidade. Antes, o orçamento era aprovado pelo Conselho Superior da APESC e a movimentação financeira era realizada pelo presidente da APESC. Estes exemplos dão a visão clara de que não havia a autonomia administrativa da Instituição de Ensino Superior exigida pela legislação no caso de Universidade. As alterações requeriam um novo Regimento Unificado para a FISC e um novo Estatuto para a APESC que foram aprovados, em instâncias finais, pelo Colegiado Superior da FISC e pela Assembleia Comunitária da APESC. Esse novo Regimento Unificado foi denominado de Regimento Unificado da Fase de Transição da FISC a Universidade, adotando a Instituição uma estrutura semelhante à escolhida para a Universidade, sem as Faculdades, com a existência dos coordenadores de curso, com a adoção das três Superintendências: de Administração, de Ensino e de Pesquisa e Extensão e com a transformação do Colegiado Superior da FISC no Conselho de Administração, adquirindo a FISC desta forma a autonomia administrativa exigida. Com a aprovação do novo Regimento, em 02/12/91 e sua entrada em vigor em 04/03/92, foi possivel que as Faculdades Integradas passassem a funcionar, a partir daquela data, como Universidade de fato, mas não de direito.

Outra alteração significativa foi a do aumento do percentual de professores com mestrado e doutorado. O Conselho Federal de Educação tem adotado como parâmetro, para estabelecimento de percentual mínimo exigido, o que prevê o projeto da nova LDB que está tramitando no Congresso Nacional e que determina que as Universidades devam ter, no mínimo, 30\% de mestres ou doutores. A FISC até o primeiro semestre de 1992 não possuía este indice e foi realizado um esforço conjunto, envolvendo todos os departamentos da FISC, para se atender a esta exigência. Foi necessário que se criasse uma Resolução a de $n^{\circ} 04$, de 23 de abril de 1992, aprovada pelo Conselho de Administração e que obrigava todos os departamentos a possuir em seus quadros pelo menos um mestre ou doutor, além de estabelecer normas para a alteração do regime de trabalho, beneficiando esses professores.

Barbarói, Santa Cruz do Sul, n.59 - número especial, p.<10-24>, Ago./Set. 2021 
Como o CFE exige também que pelo menos $20 \%$ dos professore tenham tempo integral e 50\% tenham tempo integral ou parcial, esta determinação foi trabalhada simultaneamente com a da qualificação do corpo docente.

Para dar uma visão clara da evolução, apresentados quadros comparativos da situação existente em 1990, 1991 e 1992:

Regime de Trabalho do Corpo Docente

\begin{tabular}{|c|c|c|c|c|c|c|}
\hline Regime de Trabalho & 1990 & $\%$ & 1991 & $\%$ & 1992 & $\%$ \\
\hline$T I$ & 37 & 21,0 & 49 & 29,0 & 49 & 34,0 \\
\hline$T P$ & 22 & 13,0 & 35 & 21,0 & 37 & 26,0 \\
\hline$R E$ & 117 & 66,0 & 84 & 50,0 & 58 & 40,0 \\
\hline TOTAL & 176 & 110 & 168 & 100 & 144 & 100 \\
\hline
\end{tabular}

TI - Tempo Integral (40h/s); TP - Tempo Parcial (20 a $30 \mathrm{~h} / \mathrm{s}) ;$ RE - Regime Especial (- de $20 \mathrm{~h} / \mathrm{s})$.

\section{Qualificação do Corpo Docente}

\begin{tabular}{|l|c|c|c|c|c|c|}
\hline \multicolumn{1}{|c|}{ Ano } & 1990 & $\%$ & 1991 & $\%$ & 1992 & $\%$ \\
Qualificação & & & & & & \\
\hline Graduação & 18 & 10,0 & 19 & 11,0 & 06 & 4,0 \\
Especializ,/aperf. em Andam. & 18 & 10,0 & 09 & 5,0 & - & - \\
Especialização & 90 & 51,0 & 94 & 56,0 & 57 & 40,0 \\
Mestrando & 26 & 15,0 & 21 & 13,0 & 18 & 13,0 \\
Mestrado & 17 & 10,0 & 19 & 11,0 & 38 & 26,0 \\
Doutorando & 06 & 3,5 & 03 & 2,0 & 20 & 14,0 \\
Doutorado & 01 & 1,5 & 03 & 2,0 & 05 & 3,0 \\
\hline TOTAL & 176 & 100 & 168 & 100 & 144 & 100 \\
\hline
\end{tabular}

Mas a mudança mais significativa foi a de mentalidade. Se antes era aceitável a dedicação do professor exclusivamente ao ensino, agora isto não mais admitido. Os departamentos se organizaram de forma diferente, melhorando o nível de qualificação e o tempo de dedicação dos professores, fazendo com que inúmeras atividades de pesquisa e

Barbarói, Santa Cruz do Sul, n.59 - número especial, p.<10-24>, Ago./Set. 2021 
extensão estejam sendo desenvolvidas. O número de professores que passaram a frequentar cursos de pós-graduação "stricto sensu" aumentou significativamente. A participação efetiva de professores, alunos e funcionários aumentou nas reuniões de órgãos colegiados e em seminários promovidos com o objetivo de discutir os mais variados assuntos de interesse da Instituição.

Todas essas transformações realizadas no periodo de acompanhamento, durante dois anos, foram seguidas de muitos debates, de seminários, de consulta bibliográfica, de elaboração e análise de textos e de uma reflexão profunda sobre as melhores soluções para a entidade. Procurou-se, durante todo o periodo, organizar a evolução do processo, visando às transformações de modo a conservar a unidade da Instituição, fazendo com que as divergências fossem assimiladas e as sequelas ou não existissem ou ao mesmo não fossem significativas.

Dois documentos forma produzidos pela FISC e pela Comissão de Acompanhamento: o Plano de Desenvolvimento Institucional (PDI) e o Relatório Final da Comissão de Acompanhamento. Os dois documentos apresentam uma descrição da situação anula da Instituição e fazem a projeção do seu crescimento nos próximos quatro anos e o planejamento desta expansão, destacando os setores administrativos e os campos de Ensino, da Pesquisa e da Extensão. Evidentemente não são documentos completos, mas com certeza terão profunda utilidade quando da tomada de decisões futuras. A concretização dos objetivos e metas traçados depende de diversos fatores e somente o futuro mostrará qual o percentual previsto no plano de expansão foi possível alcançar.

Ao final da fase de acompanhamento e após o reconhecimento, começamos a vivenciar a condição de Universidade e percebemos profundas diferenças que existem entre as Faculdades Integradas e a Universidade. Dessas, passamos a destacar algumas.

O último curso implantado na FISC foi o de Química Industrial em 1988, com a criação de novas vagas. Daquele ano até agora o Conselho Federal de Educação não autorizou nenhum curso novo para as Faculdades Integradas, pois, de 1988 até 1990, estava em vigor o decreto $n .93594$ que vedava o recebimento de cartas-consulta que solicitassem a autorização de novos cursos.

A Resolução n. 07, de 05/12/1989 do CFE, voltou a permitir o encaminhamento de novos pedidos. Foram então protocoladas as cartas-consulta relativas aos cursos de Análise de Sistemas e de Psicologia em 03/01/90. Os processos não evoluíram, pois surgiu o Decreto n. 49 de 05/03/91 que alterou a sistemática em torno da autorização de novos cursos.

Barbarói, Santa Cruz do Sul, n.59 - número especial, p.<10-24>, Ago./Set. 2021 
Em 02/07/92 surgiu nova Portaria que permitiu o encaminhamento de novas cartas-consulta, fixando o prazo de 16/02/93 a 31/03/93 para que os processos fossem protocolados.

Durante todo este periodo a FISC estava preparada para o oferecimento de novos cursos e os escolhidos, mais recentemente, Psicologia e Ciência da Computação o foram após várias formas de verificação de interesse da comunidade e da região e das condições da Instituição. As formas de verificação do interesse utilizadas foram: questionários preenchidos pelos vestibulandos da FISC, anualmente, de 1982 em diante; questionários encaminhados a todas as escolas de $2^{\circ}$ grau, no ano de 1991; sondagem junto às entidades sindicais, empresariais e governamentais, encaminhadas em agosto de 1991. Os dados tabulados foram analisados até 1990 pela Assessoria da Direção-Geral e, nos anos de 1991 e 1992, pela Comissão Interna de Universidade da FISC.

Com o reconhecimento da Universidade em 25/06/93, a Instituição, que já tinha os projetos dos Cursos de Psicologia e Ciência da Computação elaborados e analisados por uma Comissão designada pelo CONEPE, aprovou-os em 28/06/93 através do Conselho Universitário, após parecer favorável do Conselho de Ensino, Pesquisa e Extensão da UNISC

O vestibular foi realizado em julho/93 e os cursos já se encontravam em andamento.

Estão em fase de elaboração de projetos no momento os cursos de Enfermagem Obstetrícia e Comunicação Social - Publicidade e Propaganda e Jornalismo que são os próximos previstos no plano de expansão aprovado pela Universidade.

A possibilidade de regionalização da Universidade através da extensão de seus cursos é outra questão que tem tido tratamento diferenciado. As Faculdades Integradas eram impedidas de oferecer extensão em outros municípios por força da legislação. A Portaria $n$. 838, de 31 de maio de 1993, permite que Universidades reconhecidas pleiteiem esta autorização. Como Universidade abre-se, assim, a possibilidade de oferecimento dos cursos da Universidade de Santa Cruz do Sul em outros municípios. Esses cursos podem ser oferecidos em caráter temporário ou com a instalação de um Campus permanente, devendo os projetos elaborados, após a fase de coleta de dados, planejamento e formalização de compromissos assumidos pelas Prefeituras Municipais, serem encaminhados ao CFE para apreciação. Havendo parecer favorável, a Universidade pode partir para a execução dos projetos.

Não estamos declarando que esta é a única forma com que a UNISC vai tratar o assunto Universidade Regional, mas que no campo do Ensino Superior muitas novas possibilidades estão abertas.

Barbarói, Santa Cruz do Sul, n.59 - número especial, p.<10-24>, Ago./Set. 2021 
A condição de Universidade também traz consigo uma série de consequências que inegavelmente produzem influências positivas sobre o desenvolvimento das atividades da Instituição. A euforia e autoconfiança de professores, alunos, funcionários e comunidade é indisfarçável. O espaço destinado à UNISC nos Órgãos de Comunicação foi ampliado, possibilitando acesso inclusive à Imprensa da Capital do Estado com maior facilidade. Resta aproveitar este ambiente favorável para proporcionar condições de desenvolvimento institucional.

O crescimento da pesquisa e da extensão, devido à elevação do nível de qualificação do pessoal; à destinação de um maior volume de carga horária pela alteração do regime de trabalho dos professores e à maior integração da Instituição com setores da comunidade, é evidente. Dois projetos se destacam: o do oferecimento do Curso de Mestrado em Desenvolvimento Regional e a Implantação do Pólo de Modernização Tecnológica e podem servir de balizadores do desenvolvimento institucional, influenciando nos investimentos futuros e na definição das áreas de excelência da Universidade.

É importante que se faça no final deste artigo uma reflexão sobre os aspectos que não devem mudar apesar de todas as transformações esperadas. Deve permanecer a consciência do caráter comunitário da Instituição, o reconhecimento de que desde o início das atividades da Instituição, que agora se transforma em Universidade, a Comunidade esteve sempre presente e ofereceu seu apoio de forma concreta especialmente na formação do patrimônio que hoje possui a Associação Pró-Ensino em Santa Cruz do Sul, mantenedora da UNISC. Nesse sentido a presença do poder público do Município de Santa Cruz do Sul tem sido fundamental. A integração da UNISC com a comunidade da Região do Vale do Rio Pardo é imprescindivel para a consolidação da Universidade e execução de seu plano de expansão.

A democracia hoje existente deve ser defendida por todos os integrantes da comunidade universitária. A forma de escolha dos dirigentes da UNISC, por eleições diretas, envolvendo todos os alunos, funcionários, professores e membros da Assembleia Comunitária da APESC, já demonstrou os seus aspectos positivos durante mais de seis anos de vivência desta prática.

Essa forma de escolha dos dirigentes não garante a solução dos problemas nem o desenvolvimento institucional. O que se observa, no entanto, aqui na UNISC, é que os processos eleitorais têm servido para uma reflexão sobre a realidade da Instituição e para a tomada de posições que tem proporcionado as bases para as administrações. Um dos aspectos que deve ser destacado, e que tem origem na luta pela democratização da entidade, é que naquela época antes de se decidir a forma como os dirigentes seriam escolhidos se

Barbarói, Santa Cruz do Sul, n.59 - número especial, p.<10-24>, Ago./Set. 2021 
resolveu a forma como os dirigentes poderiam ser afastados. Hoje, o Conselho Universitário pode, a qualquer momento, destituir o Reitor da Universidade pelo voto de no mínimo dois terços de seus membros.

Esta particularidade que se observa na UNISC revela que o mandato pertence à entidade e que os compromissos assumidos pelos candidatos durante a campanha eleitoral devem ser cumpridos depois.

A constituição dos órgãos colegiados, garantindo a participação efetiva de todos os segmentos da Universidade, é um dos fatores que tem contribuído para a manutenção da democracia, pela busca permanente do atendimento das aspirações coletivas.

A transparência administrativa que se percebe na distribuição dos relatórios de auditorias, orçamentos, balancetes mensais, e balanço anual a todos os segmentos da Universidade também deve permanecer até porque o Estatuto e o Regimento Geral da UNISC estabelecem a obrigatoriedade deste procedimento.

A proposta de administração participativa deve ser continuamente aperfeiçoada. Hoje ela apresenta várias ações que permitem a participação bastante acentuada de todos os segmentos da Universidade nas decisões mais importantes.

Anualmente um instrumento de avaliação é distribuído a todos os setores, departamentos e colegiados de curso. Além da avaliação da sua organização, cada segmento avalia o conjunto da Universidade, apresentando os setores que se destacaram positiva e negativamente. Após a tabulação dos relatórios encaminhados, é realizada uma reunião com todos os Chefes de Departamentos e de Setor, com todos os Coordenadores de Curso e com a Reitoria para a análise do documento produzido, que serve de base para o estabelecimento das prioridades que serão selecionadas para a elaboração do Plano de Ação e do orçamento anual.

Entende-se que o compromisso de administrar a Universidade deve ser assumido por toda a Instituição, cabendo aos dirigentes a tarefa de coordenação do processo de tomada de decisões e de execução das atividades daí decorrentes.

O processo de transformação da FISC em Universidade não resultou apenas em uma previsão da expansão da Instituição ao longo do tempo mas também procurou fixar bases muito sólidas em uma estrutura que pretende inovar.

O trabalho está na fase inicial e esperamos que os princípios filosóficos da Universidade possam nortear as decisões da Instituição.

Para finalizar colocamos todo material citado à disposição dos interessados para consulta. Parte dele está na Biblioteca e o restante na Assessoria da Reitoria da UNISC.

Barbarói, Santa Cruz do Sul, n.59 - número especial, p.<10-24>, Ago./Set. 2021 


\title{
REPORTING AND TRANSFORMATION: THE RECOGNITION PROCESS OF THE UNIVERSITY OF SANTA CRUZ DO SUL
}

\begin{abstract}
:
The text, in addition to a short presentation, comprises a republication of an article initially published in number zero of magazine BARBARÓI. In that article, its author, Professor Wilson Kniphoff da Cruz, rescues aspects of his commitment to community higher education in Santa Cruz do Sul, recording the different moments that preceded the creation of UNISC in 1993: the mobilization of the academic community, the bureaucratic difficulties in forwarding the University project, the formation of an Internal Commission to forward the project, visits by the Monitoring Commission of the Federal Council of Education, organizational and political changes in the Institution, the repercussions of these changes in the academic community, the effort in the qualification of teachers, the necessary changes in mentality from the creation of the University. By presenting this rescue, the article is an invitation to reflect on the political dynamics that comprised the collective mobilization (especially of the academic community) aiming at the creation of a Community University in Santa Cruz do Sul.
\end{abstract}

\section{Keywords:}

Community University; Higher Education in Santa Cruz do Sul; UNISC. 